\title{
Neutrosophic analysis of variance: application to university students
}

\author{
Muhammad Aslam ${ }^{1}$ (iD
}

Received: 21 January 2019 / Accepted: 12 April 2019 / Published online: 4 May 2019

(c) The Author(s) 2019

\begin{abstract}
The existing analysis of variance (ANOVA) test cannot be applied when the sample is selected from the population having come imprecise, fuzzy and uncertain observations. The neutrosophic statistics will be applied to analyze the data having uncertain observations or the parameters. In this paper, we will introduce the neutrosophic analysis of variance (NANONA). The NANONA is an extension of the classical ANOVA. We presented the NANONA table. We performed the NANONA to test teaching methods using data collected from the university students.
\end{abstract}

Keywords Classical statistics · Neutrosophic statistics · ANOVA · NANONA · Uncertainty

\section{Abbreviations}

ANOVA
NANONA
NS
NSQC
NRV
NND
NSD
NSS
NMS
ndf
SS
$d f$
MS
$y_{N i j}$

$n_{\mathrm{N} i}$

$n_{\mathrm{NT}}$

$\bar{y}_{\mathrm{N} . .}$
Analysis of variance

Neutrosophic analysis of variance

Neutrosophic statistics

Neutrosophic statistical quality control

Neutrosophic random variable

Neutrosophic normal distribution

Neutrosophic standard deviation

Neutrosophic sum of square

Neutrosophic mean square

Neutrosophic degree of freedom

Sum of square

Degree of freedom

Mean square

The $j$ th neutrosophic sample observation from $i$ th neutrosophic population

The number of neutrosophic values chosen from $i$ th neutrosophic population

The total neutrosophic sample size The neutrosophic average from $i$ th neutrosophic population

Muhammad Aslam

aslam_ravian@hotmail.com

1 Department of Statistics, Faculty of Science, King Abdulaziz University, Jeddah 21551, Saudi Arabia

\begin{tabular}{|c|c|}
\hline$S_{\mathrm{NB}}^{2}=\mathrm{SSB}_{\mathrm{N}}$ & $\begin{array}{l}\text { Neutrosophic sum of squares } \\
\text { between groups }\end{array}$ \\
\hline$S_{\mathrm{NW}}^{2}=\mathrm{SSW}_{\mathrm{N}}$ & $\begin{array}{l}\text { Neutrosophic sum of squares within } \\
\text { groups }\end{array}$ \\
\hline NTSS & Total sum of squares \\
\hline $\begin{aligned} \mu_{\mathrm{N} 1}=\mu_{\mathrm{N} 2} & = \\
\mu_{\mathrm{N} 3}=\cdots & =\mu_{\mathrm{N} t}\end{aligned}$ & $\begin{array}{l}\text { Neutrosophic means } \\
\text { neutrosophic populations }\end{array}$ \\
\hline$F_{\mathrm{N}}$ & Neutrosophic $f$-distribution \\
\hline$\alpha$ & Level of significance \\
\hline$p_{\mathrm{N}}$-value & Neutrosophic $p$ value \\
\hline
\end{tabular}

\section{Introduction}

Statistics is the branch of the mathematical sciences, which deals with the collection, analysis and interpretation of the data. The hypothesis or statement is established, accepted, and rejected based on sample information. Among many tests, the analysis of variance (ANOVA) is an important test, which is applied, for the testing of the hypothesis that the population means of various groups or methods and population are same or not. The ANOVA is an extension of Student t-test, which is applied for the testing of the hypothesis that two populations have the same means. The analyses based on ANOVA have been widely used in a variety of fields. Armstrong et al. [9] used the ANOVA for analysis of the optometry data. Ulusoy [29] applied the ANONA for the analysis of talc particles. Tarrío-Saavedra et al. [28] used to analyze Chemometrics data. Niedoba and Pięta [22] used it 
in the mineral processing. More applications of the ANOVA can be seen in $[13,23,30]$.

The ANONA available in the literature is designed under classical statistics. Therefore, the existing ANONA technique can only be applied when all observations in the population or selected sample are determined. The existing ANOVA cannot be applied to make analysis when some observations in the population or the sample are determined. The fuzzy logic is applied when the exact measurement of the variable is not possible. Several authors worked on the ANOVA under the fuzzy approach. González-Rodríguez et al. [18] applied ANOVA on fuzzy functional data. Jiryaei et al. [19] presented the fuzzy ANOVA. Lin et al. [21] applied the ANOVA on fuzzy consumer data. More details on fuzzy ANOVA can be seen in [12, 16, 17, 20, 21, 24, 25].

A neutrosophic logic is the generalization of the fuzzy logic. The first one considers the measure of truth, false and indeterminacy. Smarandache [26] claimed that the neutrosophic logic is more efficient than the fuzzy logic. The neutrosophic statistics (NS) is introduced by Smarandache [27] which is the extension of classical statistics. The NS is applied when the sample is drawn from the population having uncertain observations. Chen et al. [14, 15] introduced the neutrosophic numbers for rock engineering issues. Aslam [10] introduced the neutrosophic statistical quality control (NSQC) the first time. Aslam [11] provided a table to explain the difference between fuzzy statistics, the NS and classical statistics. We provide the difference, advantages and limitations of classical statistics, fuzzy statistics, intuitionistic fuzzy statistics and the NS as below.

More details about the neutrosophic theory can be seen in [1-8].

By exploring the literature and according to the best of our knowledge, there is no work on ANONA under the NS. We will introduce the ANONA under the NS, called NANOVA. The proposed NANOVA can be applied under the uncertainty environment. We will present NANOVA table. It is expected that the proposed NANONA will be more flexible, effective and informative than ANOVA under classical statistics for the testing of means of various groups under the uncertainty environment. We will discuss the proposed NANOVA with the help of real data collected from university students.

\section{The neutrosophic ANOVA}

Some notations for the neutrosophic ANOVA (NANOVA) is given as

$y_{\mathrm{N} i j} \quad$ The $j$ th neutrosophic sample observation from $i$ th neutrosophic population

$n_{\mathrm{N} i} \quad$ The number of neutrosophic values chosen from $i$ th neutrosophic population

$n_{\mathrm{NT}} \quad$ The total neutrosophic sample size

$\bar{y}_{\text {N.. }} \quad$ The neutrosophic average from $i$ th neutrosophic population

$\mathrm{SSB}_{\mathrm{N}}$ Neutrosophic sum of squares between groups

$\mathrm{SSW}_{\mathrm{N}}$ Neutrosophic sum of squares within groups

NTSS Total sum of squares.

Suppose that a neutrosophic random variable (NRV) $X_{\mathrm{N}} \in$ $\left[X_{\mathrm{L}}, X_{\mathrm{U}}\right]$ is selected from a neutrosophic normal distribution

Intuitionistic fuzzy statistics

Intuitionistic fuzzy (IF) is

the extension of the

classical fuzzy logic. The

IF is considered

membership and non-membership, which belong to the real unit interval. Therefore, the statistics are based on IF will be the extension of fuzzy statistics

The fuzzy statistics will be applied only when some observations/parameters are fuzzy
The IF will be applied only when membership and non-membership, which belong to the real unit interval
Neutrosophic statistics

The neutrosophic statistics (NS) is based on the idea of neutrosophic logic. The neutrosophic logic is the extension of the fuzzy logic and considered the measure of indeterminacy. Therefore, the NS is the extension of classical statistics which deals to analyze under uncertainty

The NS is applied under the uncertainty environment. It reduces to classical statistics when all observations/parameters are determined 
Table 1 NANOVA table

\begin{tabular}{lllll}
\hline Source & $\mathrm{NSS}$ & $\mathrm{ndf}$ & $\mathrm{NMS}$ & $F_{\mathrm{N}}$ \\
\hline Between samples & $\mathrm{SSB}_{\mathrm{N}}=\mathrm{SSB}+\mathrm{ub} \mathrm{I}$ & $t_{\mathrm{N}}-1$ & $S_{\mathrm{NB}}^{2}=\mathrm{SSB}_{\mathrm{N}} / t_{\mathrm{N}}-1$ & $\frac{S_{\mathrm{NB}}^{2}}{S_{\mathrm{NW}}^{2}}$ \\
Within samples & $\mathrm{SSW}_{\mathrm{N}}=\mathrm{SSW}+\mathrm{uw} \mathrm{I}$ & $n_{\mathrm{NT}}-t_{\mathrm{N}}$ & $S_{\mathrm{NW}}^{2}=\mathrm{SSW}_{\mathrm{N}} / n_{\mathrm{NT}}-t_{\mathrm{N}}$ & \\
Totals & & $n_{\mathrm{NT}}-1$ & & \\
\hline
\end{tabular}

Table 2 The analysis of variance for various concepts

\begin{tabular}{|c|c|c|c|}
\hline Analysis of variance & $\begin{array}{l}\text { Fuzzy analysis of } \\
\text { variance }\end{array}$ & $\begin{array}{l}\text { Intuitionistic fuzzy } \\
\text { analysis of variance }\end{array}$ & $\begin{array}{l}\text { Neutrosophic analysis } \\
\text { of variance }\end{array}$ \\
\hline $\begin{array}{l}\text { This analysis of } \\
\text { variance is applied for } \\
\text { the testing of means } \\
\text { under classical } \\
\text { statistics when all the } \\
\text { observations are } \\
\text { determined }\end{array}$ & $\begin{array}{l}\text { This analysis of } \\
\text { variance is applied for } \\
\text { the testing of means } \\
\text { under fuzzy statistics } \\
\text { when some or all } \\
\text { observations are } \\
\text { fuzzy and uncertain }\end{array}$ & $\begin{array}{l}\text { This analysis of } \\
\text { variance is applied for } \\
\text { the testing of means } \\
\text { when membership } \\
\text { and non-membership, } \\
\text { which belong to the } \\
\text { real unit interval }\end{array}$ & $\begin{array}{l}\text { This analysis of } \\
\text { variance is applied for } \\
\text { the testing of means } \\
\text { when observa- } \\
\text { tions/parameters are } \\
\text { not fuzzy, in-interval. } \\
\text { The analysis of } \\
\text { variance is the } \\
\text { extension of the } \\
\text { analysis of variance } \\
\text { under classical and } \\
\text { fuzzy statistics }\end{array}$ \\
\hline
\end{tabular}

(NND) with neutrosophic mean, say $\mu_{\mathrm{N}} \in\left[\mu_{\mathrm{L}}, \mu_{\mathrm{U}}\right]$ and neutrosophic standard deviation (NSD), say $\sigma_{\mathrm{N}} \in\left[\sigma_{\mathrm{L}}, \sigma_{\mathrm{U}}\right]$, respectively. Like the ANONA in classical statistics, the ANONA under the neutrosophic statistics can be applied to test more than one neutrosophic population means simultaneously. The one way ANOVA under the neutrosophic statistics is explained as follows:

Step-1: State the null hypothesis and an alternative hypothesis that the neutrosophic population means are equal:

$H_{\mathrm{N} 0}: \mu_{\mathrm{N} 1}=\mu_{\mathrm{N} 2}=\mu_{\mathrm{N} 3}=\cdots=\mu_{\mathrm{N} t}$.

$H_{\mathrm{N} 1}$ At least one of the $t_{\mathrm{N}}$-neutrosophic populations means are not equal

Step-2: Establish the neutrosophic $F$ test:

$F_{\mathrm{N}}=\frac{S_{\mathrm{NB}}^{2}}{S_{\mathrm{NW}}^{2}} ; \quad F_{\mathrm{N}} \in\left[F_{\mathrm{L}}, F_{\mathrm{U}}\right]$

where $S_{\mathrm{NB}}^{2}=\mathrm{SSB}_{\mathrm{N}} / t_{\mathrm{N}}-1 ; S_{\mathrm{NB}}^{2} \in\left[S_{\mathrm{LB}}^{2}, S_{\mathrm{UB}}^{2}\right], S_{\mathrm{NW}}^{2}=$ $\mathrm{SSW}_{\mathrm{N}} / n_{\mathrm{NT}}-t_{\mathrm{N}} ; S_{\mathrm{NW}}^{2} \in\left[S_{\mathrm{LW}}^{2}, S_{\mathrm{UW}}^{2}\right]$. Note here that $\mathrm{SSB}_{\mathrm{N}}=\sum_{i=1}^{t_{\mathrm{N}}} n_{\mathrm{N} i}\left(\bar{y}_{\mathrm{N} i}-\bar{y}_{\mathrm{N} . .}\right) ; \mathrm{SSB}_{\mathrm{N}} \in\left[\mathrm{SSB}_{\mathrm{L}}, \mathrm{SSB}_{\mathrm{U}}\right]$ and $\mathrm{SSW}_{\mathrm{N}}=\sum_{i=1}^{t_{\mathrm{N}}} \sum_{j=1}^{n_{\mathrm{N} i}}\left(y_{\mathrm{N} i j}-\bar{y}_{\mathrm{N} i}.\right) ; \mathrm{SSW}_{\mathrm{N}} \in\left[\mathrm{SSW}_{\mathrm{L}}\right.$, $\mathrm{SSW}_{\mathrm{U}}$ ]. Finally, neutrosophic total sum of squares (NTSS) is given as follows

$\mathrm{NTSS}=S_{\mathrm{NB}}^{2}+S_{\mathrm{NW}}^{2}$

\section{Assumptions}

The assumptions for the NANOVA are given as follows
Table 3 The ALT scores

\begin{tabular}{llllll}
\hline Method & \multicolumn{1}{l}{ Test score } & & Total \\
\hline 1 & {$[80,81]$} & {$[92,92]$} & {$[87,88]$} & {$[83,83]$} & {$[342,344]$} \\
2 & {$[70,70]$} & {$[81,82]$} & {$[78,78]$} & {$[74,75]$} & {$[303,305]$} \\
3 & {$[63,64]$} & {$[76,76]$} & {$[70,71]$} & {$[80,81]$} & {$[289,292]$} \\
Total & & & & & {$[934,941]$} \\
\hline
\end{tabular}

1. To perform the NANOVA, it is assumed that the neutrosophic random sample is selected from the neutrosophic population.

2. Further, it is assumed that neutrosophic variance is the same in neutrosophic population.

The structure of the proposed NANOVA is given in Table 1.

The difference and advantages between analysis of variance, fuzzy analysis of variance, intuitionistic fuzzy analysis of variance and neutrosophic analysis of variance is explained in the following Table 2

\section{Application}

To minimize the hostility levels among the university students, a clinical psychologist is interested to perform NANONA to compare three methods. He is interested to test either the population means of all groups are equal or not. He applied the HLT test to measure the data from various students and a high HLT score shows the great hostility 
Table 4 The NANOVA table for data

\begin{tabular}{llllll}
\hline Source & NSS & ndf & NMS & $F_{\mathrm{N}}$ & $p_{\mathrm{N} \text {-value }}$ \\
\hline Between samples & {$[377.2,366.2]$} & {$[2,2]$} & {$[188.58,183.08]$} & {$[5.397,5.33]$} & {$[0.0288,0.0296]$} \\
Within samples & {$[314.5,308.7]$} & {$[9,9]$} & {$[34.94,34.31]$} & & \\
Totals & {$[691.7,6749]$} & {$[11,11]$} & & & \\
\hline
\end{tabular}

Table 5 The ANOVA table for data

\begin{tabular}{llrrrr}
\hline Source & SS & \multicolumn{1}{c}{$d f$} & \multicolumn{1}{c}{ MS } & \multicolumn{1}{l}{$F$} & $p$-value \\
\hline Between samples & 366.2 & 2 & 183.08 & 5.33 & 0.0296 \\
Within samples & 308.7 & 9 & 34.31 & & \\
Totals & 6749 & 11 & & & \\
\hline
\end{tabular}

levels. The twelve students are selected for this test. Four students are randomly selected and placed in a group and treated with method 1. Four students from eight students are again selected at random and treated with method 2. Four students from four students are again selected at random and treated with method 3. While measuring HLT scores, the clinical psychologist is uncertain in some scores. Under this situation, he recorded data in the neutrosophic interval. Therefore, the ANOVA under classical statistics cannot be applied for the testing of means among groups. The alternative test is NANONA for the testing of means. The data is shown in Table 3. For the data given in Table 3, the existing ANOVA under classical statistics cannot be applied for testing either three methods are equal in means or not. Therefore, the proposed NANOVA is a reasonable alternative for this data.

The sum of squares between samples, within sample and totals, as shown in Table 4. Smarandache [27] discussed the rules of the $p$ value for the neutrosophic data. Let $p_{\mathrm{N}}$-value denotes the $p$ value for the neutrosophic statistics. According to rules, the null hypothesis that three means are equal will be rejected if $\max \left\{p_{\mathrm{N}}\right.$-value $\} \leq \alpha$, where $\alpha$ is a level of significance. For this real data, $\max \left\{p_{\mathrm{N}}\right.$-value $\left.=0.0295\right\} \leq 0.05$, we reject the hypothesis that the means of three methods are the same. Table 4 presented all sum of squared in indeterminacy interval. The ANOVA under classical statistics is shown in Table 5. From Table 5, we note that all values in ANOVA table are determined. By comparing both tables, it is concluded that the proposed NANONA is a more adequate method than the methods under classical statistics.

\section{Conclusions}

In this paper, an ANOVA under the NS is presented. The proposed NANOVA is the generalization of the existing ANOVA under classical statistics. The proposed methods have the ability to be applied effectively than the existing under uncertainty. A NANOVA table from a real example shows that sum squares were in indeterminacy interval. We recommend applying the proposed ANONA for testing of the means in a variety of fields under uncertainty. The post hoc tests under the neutrosophic NANOVA can be considered as future research.

Acknowledgements The authors are deeply thankful to the editor and the reviewers for their valuable suggestions to improve the quality of this manuscript.

Open Access This article is distributed under the terms of the Creative Commons Attribution 4.0 International License (http://creativecomm ons.org/licenses/by/4.0/), which permits unrestricted use, distribution, and reproduction in any medium, provided you give appropriate credit to the original author(s) and the source, provide a link to the Creative Commons license, and indicate if changes were made.

\section{References}

1. Abdel-Basset M, Atef A, Smarandache F (2018) A hybrid Neutrosophic multiple criteria group decision making approach for project selection. Cogn Syst Res. https://doi.org/10.1016/j.cogsys. 2018.10.023

2. Abdel-Basset M, Gunasekaran M, Mohamed M, Chilamkurti N (2019) A framework for risk assessment, management and evaluation: economic tool for quantifying risks in supply chain. Future Gener Comput Syst 90:489-502

3. Abdel-Basset M, Gunasekaran M, Mohamed Met al (2018) A novel method for solving the fully neutrosophic linear programming problems. Neural Comput Appl. https://doi.org/10.1007/s00521018-3404-6

4. Abdel-Basset M, Manogaran G, Gamal A et al (2018) A hybrid approach of neutrosophic sets and DEMATEL method for developing supplier selection criteria. Des Autom Embed Syst 22(3):257-278. https://doi.org/10.1007/s10617-018-9203-6

5. Abdel-Basset M, Manogaran G, Mohamed M, Chilamkurti N (2018) Three-way decisions based on neutrosophic sets and AHPQFD framework for supplier selection problem. Future Gener Comput Syst 89:19-30

6. Abdel-Basset M, Mohamed M, Chang V (2018) NMCDA: a framework for evaluating cloud computing services. Future Gener Comput Syst 86:12-29

7. Abdel-Basset M, Mohamed M, Smarandache F (2018) An extension of neutrosophic AHP-SWOT analysis for strategic planning and decision-making. Symmetry 10:116

8. Abdel-Basset M, Zhou Y, Mohamed M, Chang V (2018) A group decision making framework based on neutrosophic VIKOR approach for e-government website evaluation. J Intell Fuzzy Syst 34:4213-4224

9. Armstrong RA, Eperjesi F, Gilmartin B (2002) The application of analysis of variance (ANOVA) to different experimental designs in optometry. Ophthalmic Physiol Opt 22:248-256

10. Aslam M (2018) A new sampling plan using neutrosophic process loss consideration. Symmetry 10:132 
11. Aslam M (2019) A new attribute sampling plan using neutrosophic statistical interval method. Complex Intell Syst. https://doi.org/10. 1007/s40747-018-0088-6

12. Blanco-Fernández A, Casals M, Colubi A, Corral N, GarciaBárzana M, Gil M, González-Rodrıguez G, López M, Lubiano M, Montenegro M (2013) Random fuzzy sets: a mathematical tool to develop statistical fuzzy data analysis. Iran J Fuzzy Syst 10:1-28

13. Borgonovo E, Morris MD, Plischke E (2018) Functional ANOVA with multiple distributions: implications for the sensitivity analysis of computer experiments. SIAM/ASA J Uncertain Quantif $6: 397-427$

14. Chen J, Ye J, Du S (2017) Scale effect and anisotropy analyzed for neutrosophic numbers of rock joint roughness coefficient based on neutrosophic statistics. Symmetry 9:208

15. Chen J, Ye J, Du S, Yong R (2017) Expressions of rock joint roughness coefficient using neutrosophic interval statistical numbers. Symmetry 9:123

16. De Andres-Sánchez J (2012) Claim reserving with fuzzy regression and the two ways of ANOVA. Appl Soft Comput 12:2435-2441

17. García JCF, Kalenatic D, Bello CAL (2009) On the robustness of type- 1 and type-2 fuzzy tests vs. ANOVA tests on means. In: Huang DS, Jo KH, Lee HH, Kang HJ, Bevilacqua V (eds) Emerging intelligent computing technology and applications. With aspects of artificial intelligence. ICIC 2009. Lecture notes in computer science, vol 5755. Springer, Berlin, pp 174-183

18. González-Rodríguez G, Colubi A, Gil MÁ (2012) Fuzzy data treated as functional data: a one-way ANOVA test approach. Comput Stat Data Anal 56:943-955

19. Jiryaei A, Parchami A, Mashinchi M (2013) One-way ANOVA and least squares method based on fuzzy random variables. Turk $\mathbf{J}$ Fuzzy Syst 4:18-33

20. Lee W-J, Jung H-Y, Yoon JH, Choi SH (2017) Analysis of variance for fuzzy data based on permutation method. Int J Fuzzy Log Intell Syst 17:43-50

21. Lin PC, Arbaiy N, Hamid IRA (2017) One-way ANOVA model with fuzzy data for consumer demand. In: Herawan T, Ghazali R, Nawi N, Deris M (eds) Recent advances on soft computing and data mining. SCDM 2016. Advances in intelligent systems and computing, vol 549. Springer, Berlin, pp 111-121
22. Niedoba T, Pięta P (2016) Applications of ANOVA in mineral processing. Min Sci 23:43-54

23. Ozturk S (2014) Application of ANOVA and Taguchi methods for evaluation of the surface roughness of Stellite- 6 coating material. Mater Test 56:1015-1020

24. Parthiban S, Gajivaradhan P (2016) One-factor ANOVA model using trapezoidal fuzzy numbers through alpha cut interval method. Ann Pure Appl Math 11:45-61

25. Peña $M$, Cerrada $M$, Alvarez X, Jadán D, Lucero $P$, Milton $B$, Guamán R, Sánchez R-V (2018) Feature engineering based on ANOVA, cluster validity assessment and KNN for fault diagnosis in bearings. J Intell Fuzzy Syst 34:3451-3462

26. Smarandache F (2010) Neutrosophic logic — a generalization of the intuitionistic fuzzy logic. In: Multispace \& multistructure. Neutrosophic transdisciplinarity (100 collected papers of science), vol 4, p 396

27. Smarandache F (2014) Introduction to neutrosophic statistics. Infinite Study, Conshohocken

28. Tarrío-Saavedra J, Naya S, Francisco-Fernández M, Artiaga R, Lopez-Beceiro J (2011) Application of functional ANOVA to the study of thermal stability of micro-nano silica epoxy composites. Chemom Intell Lab Syst 105:114-124

29. Ulusoy U (2008) Application of ANOVA to image analysis results of talc particles produced by different milling. Powder Technol 188:133-138

30. Zhang J-T, Cheng M-Y, Tseng C-J, Wu H-T (2013) A new test for one-way ANOVA with functional data and application to ischemic heart screening. arXiv preprint. arXiv:1309.7376

Publisher's Note Springer Nature remains neutral with regard to jurisdictional claims in published maps and institutional affiliations. 